\title{
Update on management of stable chronic obstructive pulmonary disease
}

\author{
Ritwick Agrawal $^{1,2}$, Shahram Moghtader ${ }^{1,2}$, Uma Ayyala $^{1,2}$, Venkata Bandi $^{1,2}$, Amir Sharafkhaneh $^{1,2}$ \\ ${ }^{1}$ Section of Pulmonary, Critical Care, and Sleep Medicine, Department of Medicine, Baylor College of Medicine, Houston, TX, USA; ${ }^{2}$ Section of \\ Pulmonary, Critical Care, and Sleep Medicine, Medical Care Line, Michael E. DeBakey VA Medical Center, Houston, TX, USA \\ Contributions: (I) Conception and design: All authors; (II) Administrative support: All authors; (III) Provision of study materials or patients: All \\ authors; (IV) Collection and assembly of data: All authors; (V) Data analysis and interpretation: All authors; (VI) Manuscript writing: All authors; (VII) \\ Final approval of manuscript: All authors. \\ Correspondence to: Amir Sharafkhaneh, MD, PhD. Professor of Medicine, Baylor College of Medicine, 2002 Holcombe Blvd., Houston, TX 77025, \\ USA. Email: amirs@bcm.edu.
}

\begin{abstract}
Chronic obstructive pulmonary disease (COPD) is a major chronic debilitating condition with significant impact on quality of life, symptoms, comorbidity, health care utilization and longevity. The main pathophysiological hallmark of COPD is expiratory flow limitation which impairs the ability of respiratory system to adequately and properly ventilate. To be able to prognosticate and manage patients with COPD, various societies have developed classifications of disease severity. Current classification schemes combine three elements that include lung function, patient reported symptoms (shortness of breath) and frequency of exacerbations. Global Initiative for Obstructive Lung Disease (GOLD), an international guideline for diagnosis and management of COPD, started using this approach since the 2011 revision. Management according to this scheme has been developed and is in use. Comprehensive COPD management is multifaceted. It includes pharmacologic management, patient education, smoking cessation, influenza and pneumococcal vaccinations, depression and anxiety management, pulmonary rehabilitation, and if indicated, home oxygen therapy. The following chapter will review management recommendations currently in use for stable COPD. We intend to make the chapter to the point and practical and avoid an exhaustive review of the literature.
\end{abstract}

Keywords: Pharmacotherapy; bronchodilator; disease management

Submitted May 02, 2019. Accepted for publication May 31, 2019.

doi: $10.21037 /$ jtd.2019.06.12

View this article at: http://dx.doi.org/10.21037/jtd.2019.06.12

\section{Introduction}

Chronic obstructive pulmonary disease (COPD) is a major chronic debilitating condition with significant impact on quality of life, symptoms, comorbidity, health care utilization and longevity. Clinically, COPD is characterized by gradual development of shortness of breath, cough, sputum production, and repeated episodes of acute worsening of respiratory status called COPD exacerbation. Cigarette smoking is the main cause of COPD. The main pathophysiological hallmark of COPD is expiratory flow limitation which impairs the ability of the respiratory system to adequately and properly ventilate. The expiratory flow limitation is caused by loss of elastic recoil support provided by alveolar attachments around the small airways, by inflammation and scarring of small airway walls, and by accumulation of mucus in the lumen of small airways. In addition, destruction of the lung parenchyma impairs the lung's ability to participate in gas exchange. Chronic inflammation is the main cause of changes seen in COPD (1).

To be able to prognosticate and manage patients with COPD, various societies have developed classifications of disease severity. Although initial classifications revolved around objective measures of lung function, practitioners 
very soon recognized that patients with similar lung function impairments report various degrees of functional and subjective limitations. The newer classification scheme combines three elements that include lung function, patient reported symptoms (shortness of breath) and frequency of exacerbations. Global Initiative for Obstructive Lung Disease (GOLD), an international guideline for diagnosis and management of COPD, started using this approach since the 2011 revision (2). Management according to this scheme has been developed and is in use. Comprehensive COPD management is multifaceted. It includes pharmacologic management, patient education, smoking cessation, influenza and pneumococcal vaccination, depression and anxiety management, pulmonary rehabilitation, and if indicated, home oxygen therapy (1). The following chapter will review management recommendations currently in use for stable COPD.

\section{Smoking cessation}

Tobacco smoking is the main cause of COPD. Smoking cessation has the greatest capacity among all intervention modalities to influence the natural history of COPD. However, smoking cessation is not easy and on average, a smoker may try to quit several times before succeeding. Overall, the long-term tobacco cessation success rate is about $25 \%$ (3). The success rate has been shown to improve with implementation of smoking bans in addition to individual smoking cessation attempts (4).

\section{Pharmacotherapies and non-pharmacotherapies for the smoking cessation}

Nicotine replacement therapies such as nicotine gum, inhaler, transdermal patch, lozenge, sublingual tablet and nasal spray can increase smoking cessation success rates compared with placebo (5). The contraindications to nicotine replacement therapy are recent myocardial ischemia or stroke. Although controversial, it is suggested that after an acute coronary syndrome, nicotine replacement be started 2 weeks or later from the event onset $(6,7)$.

E-cigarettes as smoking cessation agents are controversial despite their increasing use in this setting (7-11). Additionally, their overall safety has not been established and some organizations advocate for caution about their usage due to the paucity of safety data. Recent data suggest that these agents alter lung host response in smokers $(12,13)$.

Other pharmacologic products such as varenicline, bupropion and nortriptyline have been shown to increase the smoking cessation rate; however, they are best used as part of a supportive care component in smoking cessation to improve the cessation outcome (14-16).

The 5-step intervention program to include ASK, ADVISE, ASSESS, ASSIST and ARRANGE provides a reasonable strategy for providers helping patients quit smoking (5). As tobacco addiction is a chronic condition, the relapse rate is high and the providers should be aware of this without blaming either themselves or the patient for the relapse.

It is noteworthy that counseling provided by any of the healthcare professionals including a brief 3 -minute session significantly increases the quit rate (17). It has also been shown that counseling intensity increases the quit rate success (18). Overall, counseling support has been shown to improve the tobacco cessation success rate at 6 months compared with the usual care (19). The combination of behavioral and counseling support in addition to pharmacotherapy has also been shown to improve the quit rate further (20).

\section{Vaccination}

Influenza vaccination reduces hospitalization due to lower respiratory tract infections leading to hospitalization and death in patients with COPD (21-24). Additionally, despite the paucity of studies evaluating COPD exacerbations, there appears to be evidence of significant reduction in the number of exacerbations in vaccinated COPD patients compared with those who received placebo (21). Vaccination with either live attenuated or killed virus is recommended as they are both effective in the elderly COPD patients (25). Additionally, a population-based study suggests that COPD patients and particularly elderly ones had a reduction in the risk of ischemic heart disease in influenza vaccinated patients and when these events occurred they were generally milder and more transient (26).

Pneumococcal vaccination with Pneumococcal Vaccine 13 (PCV13) and Pneumococcal Polysaccharide Vaccine 23 (PPSV23) are both recommended for all patients ages 65 or older. However, the PPSV23 is recommended for most younger COPD patients with significant chronic lung and/or chronic heart disease (27). Of note, specific recommendations regarding the efficacy of PCV13 and PPSV23 are limited and contradictory (28). Overall, the vaccination has been shown to reduce the risk of COPD exacerbation and therefore it is recommended in COPD 


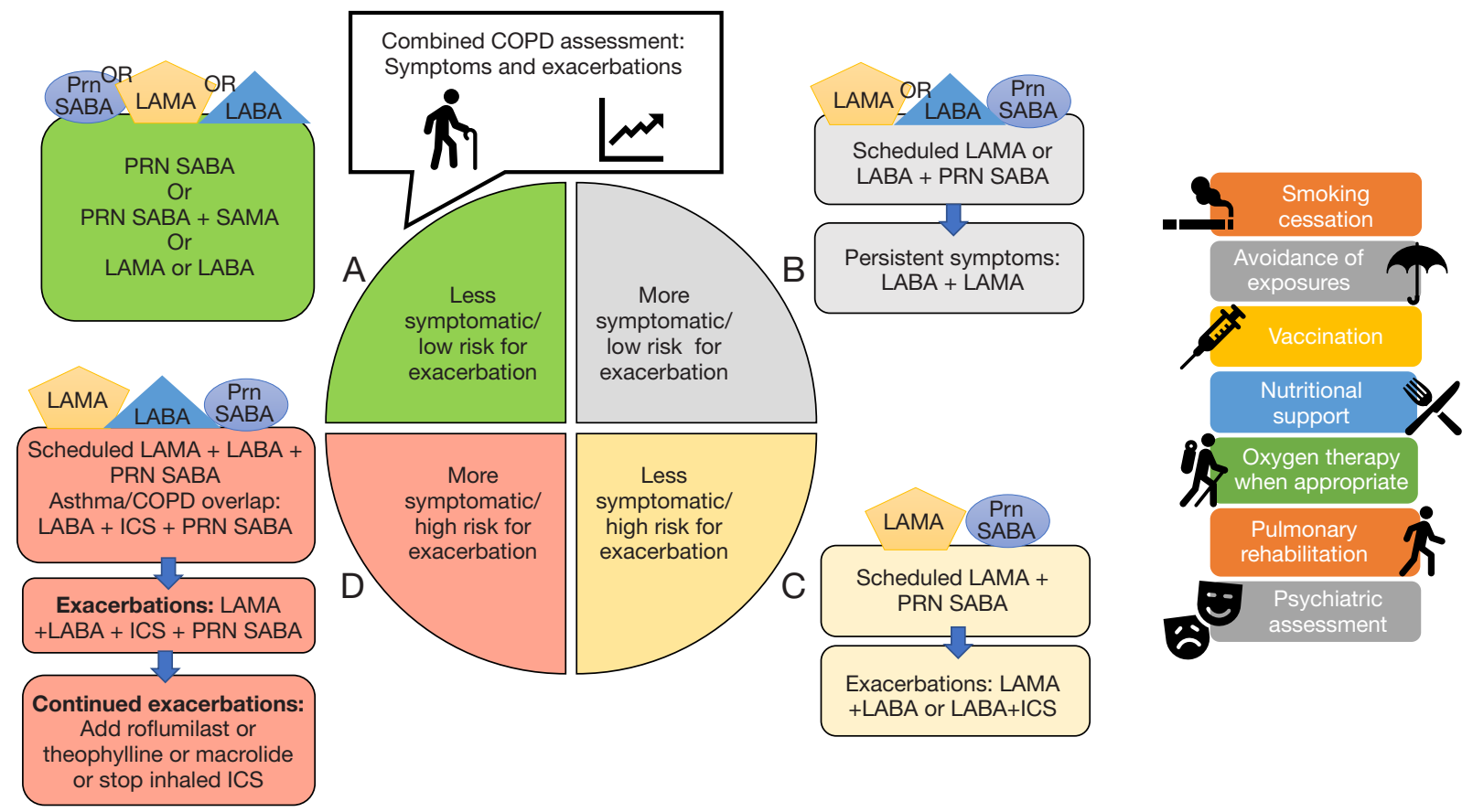

Figure 1 Management of stable COPD. SABA, short-acting bronchodilator agonist; LAMA, long-acting muscarinic antagonist; LABA, long-acting $\beta 2$ agonist; SAMA, short-acting muscarinic agonist; PRN, pro re nata; COPD, chronic obstructive pulmonary disease; ICS, inhaled corticosteroids.

patients with a moderate quality of evidence. However, evidence comparing which type of vaccine is best in these patients was insufficient (29). The incidence of community acquired pneumonia was reduced in severe COPD patients younger than 65 with an FEV $1<40 \%$ of predicted and in those with cardiac comorbidities who received the PPSV23 vaccine (30). The PCV13 also has been shown to induce at least the same or higher immunogenicity of the PPSV23 vaccine in COPD patients for up to 2 years after the vaccination (31). Additionally, a large randomized controlled trial 1 has shown that the PCV13 vaccine had a significant efficacy for the prevention vaccine-type community-acquired pneumonia (45.6\%) and vaccine-type invasive pneumococcal disease $(75 \%)$ among adults age 65 or older and this efficacy lasted for at least 4 years $(1,32)$.

In summary, yearly influenza vaccination is recommended for all stable COPD patients (Evidence B). The pneumococcal PPSV23 is recommended in younger patients with COPD and FEV1 than $40 \%$ of predicted (Evidence $\mathrm{B}$ ). The pneumococcal PCV13 vaccination is recommended in all patients 65 and older as the evidence has shown that it reduces the risk of bacteremia and serious invasive pneumococcal disease (Evidence B).

\section{Pharmacotherapy of stable COPD}

The general principles of pharmacotherapy in COPD are initiation of medications based on individual patient phenotype and GOLD stratification with the three main goals of (I) alleviation of symptoms, (II) reduction in future complications including acute exacerbations of COPD and (III) improvement in exercise tolerance and quality of health (1). These medications are further classified into inhaled monotherapy, inhaled combination therapy, and systemic treatments (see Figure 1 and Tables 1-3)

\section{Bronchodilators}

Bronchodilators, medications that relieve bronchial obstruction through airway smooth muscle relaxation, are the cornerstone of therapy in COPD. They have been shown to reduce air trapping both at rest and during exercise $(1,44)$. Bronchodilators can be classified into two major groups based on their mechanism of action, $\beta 2$-agonists and muscarinic receptor (M1, M2, and M3) antagonists. Within $\beta 2$ agonists and muscarinic receptor antagonists, there are both short acting (short-acting $\beta 2$ 
Table 1 Inhaled bronchodilators

\begin{tabular}{llll}
\hline $\begin{array}{l}\text { Class of } \\
\text { medication }\end{array}$ & Available medications & Benefits when compared to placebo & Adverse effects \\
\hline SABA and & Albuterol & Improves symptoms & SABA: Headache, tachycardia, tremors, hypokalemia \\
SAMA (33,34) & Levalbuterol & SAMA: Dry mouth, Nausea, metallic taste, urinary retention \\
& Ipratropium & & \\
& Albuterol/ipratropium & & Same as SABA \\
LABA (35) & Indacaterol & Improves FEV1 & \\
& Salmeterol & Reduces SGRQ & Same as SAMA \\
& Olodaterol & Reduces AE & \\
LAMA (36,37) & Umeclidinium & Improves FEV1 & \\
& Glycopyrrolate & Reduces SGRQ & \\
& Tiotropium & Reduces AE & \\
& Aclidinium & &
\end{tabular}

SABA, short-acting bronchodilator agonist; SAMA, short-acting muscarinic agonist; FEV1, forced expiratory volume in 1 second; LABA, long-acting $\beta 2$ agonist; SGRQ, St. George Respiratory Questionnaire score; AE, acute exacerbation risk reduction; LAMA, long-acting muscarinic antagonist.

Table 2 Inhaled combination therapy

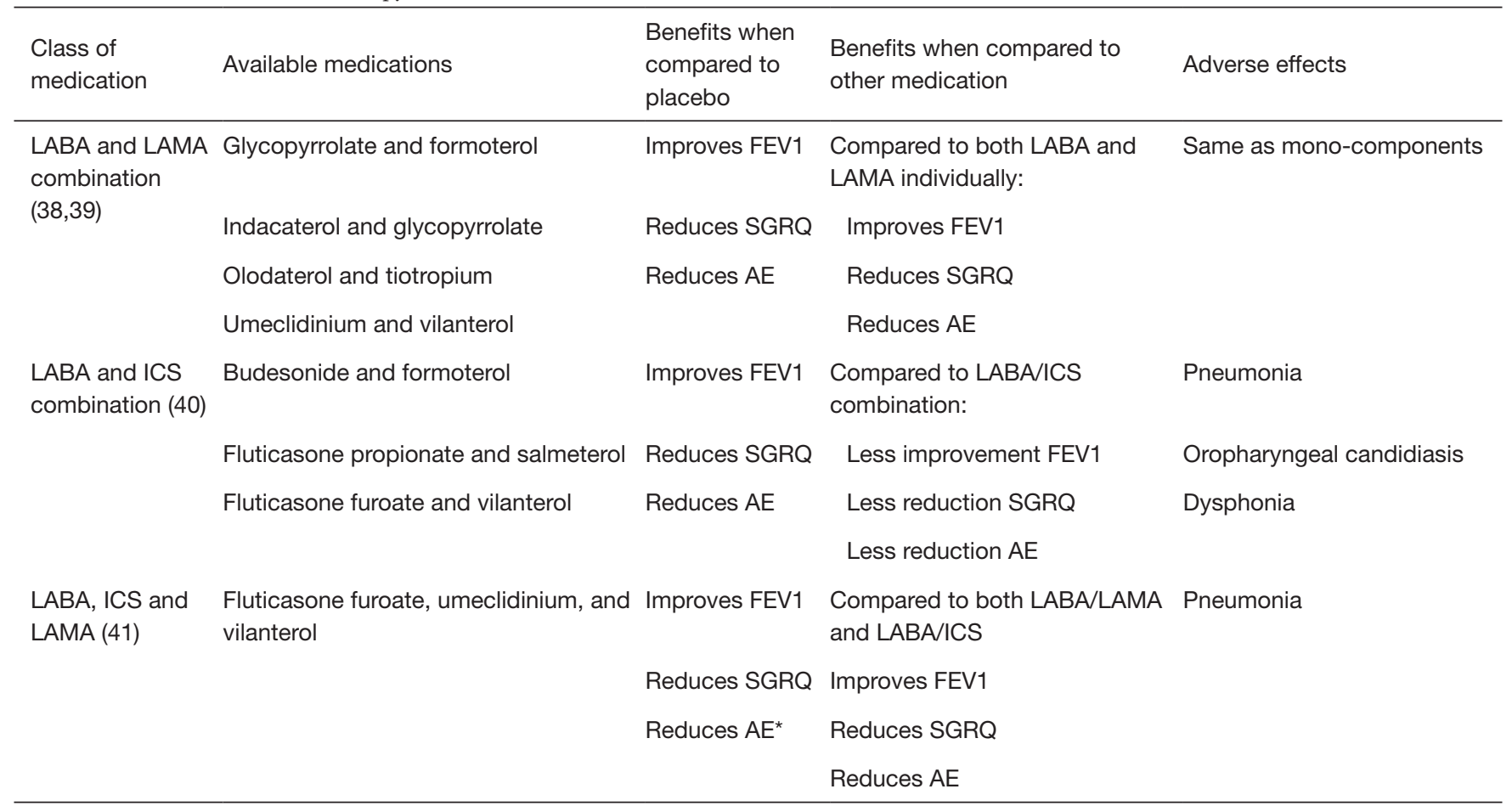

*, greatest benefit in patients with eosinophils $>300$ cells $/ \mu \mathrm{L}$. SABA, short-acting bronchodilator agonist; SAMA, short-acting muscarinic agonist; FEV1, forced expiratory volume in 1 second; LABA, long-acting $\beta 2$ agonist; SGRQ, St. George Respiratory Questionnaire score; $\mathrm{AE}$, acute exacerbation risk reduction; LAMA, long-acting muscarinic antagonist; ICS, inhaled corticosteroid. 
Table 3 Systemic therapies

\begin{tabular}{llll}
\hline $\begin{array}{l}\text { Class of } \\
\text { medication }\end{array}$ & $\begin{array}{l}\text { Available } \\
\text { medications }\end{array}$ & $\begin{array}{l}\text { Benefits when } \\
\text { compared to } \\
\text { placebo }\end{array}$ & Adverse effects \\
\hline $\begin{array}{llll}\text { PDE4 } \\
\text { inhibitors (42) }\end{array}$ & Roflumilast & $\begin{array}{l}\text { Increases FEV1 } \\
\text { Reduces SGRQ }\end{array}$ & Diarrhea \\
& & Reduces AE & $\begin{array}{l}\text { Exacerbation } \\
\text { of psychiatric } \\
\text { disorders }\end{array}$ \\
& Azithromycin & Reduces SGRQ & $\begin{array}{l}\text { Hearing } \\
\text { impairment }\end{array}$ \\
& & Reduces AE & Arrhythmias \\
\hline
\end{tabular}

PDE4, phosphodiesterase 4; FEV1, forced expiratory volume in 1 second; St. George Respiratory Questionnaire score; AE, acute exacerbation risk reduction.

agonist or SABA and short-acting muscarinic antagonist or SAMA) and long acting (long-acting $\beta 2$ agonist or LABA and long-acting muscarinic antagonist or LAMA) therapies.

\section{Short acting bronchodilators}

Inhaled $\beta 2$-agonists act through stimulation of $\beta 2$-receptors in bronchial smooth muscle cells, increasing cyclic adenosine monophosphate (cAMP) and promoting airway relaxation and bronchodilation. Inhaled SABAs such as albuterol and levalbuterol have onset of action within 5-10 minutes and duration of 4-6 hours (34). Inhaled muscarinic antagonists block muscarinic receptors (M1, M2, and M3), thereby inhibiting the acetylcholine induced bronchial smooth muscle constriction. Ipratropium is a SAMA with effects lasting up to 8 hours (34). Both SABA and SAMA improve FEV1 and symptom relief in patients with all stages of COPD but should be not used as scheduled mono-therapy. Though there is no data to support SABA over SAMA monotherapy, combination therapy is superior to either medication alone in improving FEV1 and symptoms $(33,34)$.

\section{Long acting bronchodilators}

Inhaled LABAs have bronchodilatory effects that last from 12 hours (formoterol or salmeterol) to 24 hours (indacaterol, olodaterol or vilanterol). Similarly, LAMAs have effects from 12 hours (aclidinium) to 24 hours (glycopyrronium, tiotropium, or umeclidinium). Both classes of medications are recommended as first-line therapy for patients with higher symptom burden, exacerbations, or more severely impaired lung function (GOLD B-D). Both LABAs and LAMAs have been shown to improve FEV1, symptom scores, and reduce exacerbations $(35,37)$. There are some data to support an advantage of tiotropium over LABAs as the most effective single agent in reducing exacerbations $(36,37)$.

There are four FDA approved combination LABA/ LAMA therapies (see Table 2). Combination LABA/ LAMA therapies have shown greater efficacy in improving lung function, symptom burden and quality of life measures and in some studies, a reduction in moderate to severe exacerbation risk when compared with individual components $(38,39)$. Of the four combination therapies, only indacaterol/glycopyrronium has demonstrated a reduction in exacerbation rate when compared to both LAMA and LABA/inhaled corticosteroids (ICS) (45). Current literature supports the safety of LABA/LAMA combination therapy with no increase in adverse events including cardiovascular events when compared with individual components $(38,40)$.

\section{ICS}

Monotherapy with ICS is not recommended and has not shown any benefit with respect to improvement in lung function or mortality (46). In addition, treatment with ICS alone has been associated with increased risk of pneumonia, oropharyngeal candidiasis and hoarseness (46).

\section{Combination inbalational therapies}

Currently, combination dual and triple therapies are available in the market and approved by the FDA. Combination LABA/LAMA was discussed above. Combination of ICS and LABA improves lung function and quality of life and reduces acute exacerbations more than single components. Triple combination also improves lung function and quality of life and reduces rate of moderate or severe acute exacerbation more than single components (Table 2) (47).

\section{Systemic corticosteroids}

Systemic corticosteroids should be used in patients suffering from acute exacerbations of COPD and should not be used chronically for patients with stable COPD $(48,49)$. A recent meta-analysis corroborates that a short course of oral 
corticosteroids ( $3-7$ days) is as effective as longer durations of treatment (10-15 days) with regards to treatment failure, relapse and time to next exacerbation with no difference in side effects (50).

\section{PD4 inbibitors}

Roflumilast is a selective inhibitor of phosphodiesterase-4 (PDE4) that increases intracellular cAMP leading to a variety of anti-inflammatory effects (51). Roflumilast is an oral medication initiated at $250 \mu \mathrm{g}$ for the first four weeks and then continued at $500 \mu \mathrm{g}$ daily (52). Roflumilast has demonstrated improvement in lung function in patients with moderate to severe COPD and decreased moderate exacerbations by $12.3 \%$ and severe exacerbations by $16.1 \%$ in patients with severe COPD associated with chronic bronchitis phenotype and a history of exacerbations $(42,53)$. The most common adverse events with roflumilast include diarrhea, weight loss and insomnia and depressive mood symptoms, so caution should be taken when prescribing to patients who are underweight or have depression (42).

\section{Macrolides}

Macrolide antibiotics such as azithromycin have been shown to reduce exacerbations by $27 \%$ when taken daily (43). This is thought to be due to its immunomodulatory, anti-inflammatory and anti-bacterial properties at the expense of possible reversible hearing impairment and arrhythmias. This should be considered in patients who have exacerbations while on maximal inhaler therapy.

\section{Stepwise approach to pharmacotherapy}

Comprehensive COPD management is multifaceted. It includes pharmacologic management, patient education, smoking cessation, influenza and pneumococcal vaccination, depression and anxiety management, pulmonary rehabilitation, and if indicated, home oxygen therapy. The pharmacologic treatment choice primarily depends on two factors: (I) severity of symptoms and (II) frequency of exacerbations. There are multiple validated tools to objectively assess the severity of symptoms such as modified Medical Research Council (mMRC) and COPD Assessment Test (CAT). Frequency of exacerbations can be assessed based on number of exacerbations managed on outpatient basis and those that require hospitalization. In patients with stable COPD, once the severity of symptoms and episodes of exacerbations are determined, medications can be started based on the COPD-GOLD framework (Figure 1). This classification provides a general framework which revolves around the following principles. In patients with limited symptoms and without exacerbations (group A), usually one bronchodilator is adequate. Short acting medications may be adequate to manage these patients, though in some cases, LAMA or LABA may be indicated. In patients with an exacerbation phenotype, LAMA has been shown to be superior, while in patients with an asthmatic phenotype, addition of ICS has shown to be helpful. If a single long-acting bronchodilator is not completely effective, combination therapy with LAMA and LABA is recommended. In COPD patients with high symptom burden (usually group D) and several exacerbations, "triple therapy" has been shown to be superior. Triple therapy involves a combination of LAMA, LABA and ICS (54-56). For patients who have chronic bronchitis with persistent symptoms despite triple therapy, addition of roflumilast should be considered. Macrolides for their anti-inflammatory benefits may be considered in those who are smokers.

With the complexity of pharmacologic therapy, nonpharmacologic therapy and risk reduction can be under appreciated (see smoking cessation and vaccination).

Once the initial therapy has been selected, close follow up to escalate and deescalate the pharmacologic therapy is indicated. Figure 1 provides a general framework of treatment options for escalation and de-escalation. During the follow-up visits, in addition to clinical improvement, side effect profile should be considered. Several of these medications have significant side effects and associated risks which should be closely weighted with the benefits. For example, ICS are associated with a 1.57 -fold increased risk for bacterial pneumonia (46). Patient education also plays a significant role in the overall management. Incorrect inhaler technique is a major factor contributing to treatment failure. Education about correct inhaler technique in addition to overall disease process either in individual and group settings has been shown to improve outcomes. Attention to patient's and care giver's inhaler device preferences is important (57). Prevalence of comorbid depression and anxiety is higher in patients with COPD compared to those without (58). This may lead to fatigue and ultimately activity avoidance. Screening of psychological conditions and comprehensive management with pulmonary rehabilitation improves symptoms, quality 
of life, pulmonary function, and health care utilization.

\section{Pulmonary rehabilitation}

Respiratory rehabilitation is a multifaceted program encompassing several factors to improve the symptoms in COPD patients. A typical program is interdisciplinary and includes strength and endurance training as well as educational, psychological and nutritional training. These programs can improve cardiovascular fitness, symptoms and physical activity levels in patients with COPD (59).

Additionally, pulmonary rehabilitation has been shown to exceed improvements in dyspnea, exercise tolerance and quality of life to a degree that is greater than pharmacological therapies alone (60). Studies have shown that early respiratory rehabilitation following hospitalization for acute COPD exacerbation improves mortality [relative risk (RR) $0.58,10 \%$ vs. $17.3 \%$ ] and reduces the hospital readmission rate (RR 0.47) (61). Despite all these benefits, less than $5 \%$ of the eligible candidates receive the pulmonary rehabilitation (62). A typical respiratory rehabilitation program is attended about 2 to 3 times per week as part of overall COPD management. Medicare coverage however is limited to a maximum of 36 sessions with the option of an additional 36 sessions based on medical necessity.

\section{Summary}

COPD is a chronic medical condition with significant morbidity and mortality. A comprehensive assessment draws on subjective and objective data to classify patients in various severity and management groups. Vaccination and smoking cessation are indicated in all COPD patients. Bronchodilator therapy is the main recommended therapy. They improve symptoms, quality of life, lung function and exercise capacity, and reduce COPD exacerbation rate. Various anti-inflammatory agents may play a role in COPD management. They, in combination with long acting bronchodilators, improve various clinical outcomes. Further, patient education about the disease and about correct use of the prescribed medication is very important in a comprehensive management of this disease.

\section{Acknowledgments}

The current work is supported by Veteran Health Administration.

\section{Footnote}

Conflicts of Interest: The authors have no conflicts of interest to declare.

\section{References}

1. Singh D, Agusti A, Anzueto A, et al. Global Strategy for the Diagnosis, Management, and Prevention of Chronic Obstructive Lung Disease: the GOLD science committee report 2019. Eur Respir J 2019. doi: 10.1183/13993003.00164-2019.

2. Johannessen A, Nilsen RM, Storebo M, et al. Comparison of 2011 and 2007 Global Initiative for Chronic Obstructive Lung Disease guidelines for predicting mortality and hospitalization. Am J Respir Crit Care Med 2013;188:51-9.

3. van Eerd EA, van der Meer RM, van Schayck OC, et al. Smoking cessation for people with chronic obstructive pulmonary disease. Cochrane Database Syst Rev 2016;(8):CD010744.

4. Frazer K, Callinan JE, McHugh J, et al. Legislative smoking bans for reducing harms from secondhand smoke exposure, smoking prevalence and tobacco consumption. Cochrane Database Syst Rev 2016;2:CD005992.

5. A clinical practice guideline for treating tobacco use and dependence: A US Public Health Service report. The Tobacco Use and Dependence Clinical Practice Guideline Panel, Staff, and Consortium Representatives. JAMA 2000;283:3244-54.

6. Lee PN, Fariss MW. A systematic review of possible serious adverse health effects of nicotine replacement therapy. Arch Toxicol 2017;91:1565-94.

7. McNeill A, Brose LS, Calder R, et al. E-cigarettes: the need for clear communication on relative risks. Lancet 2015;386:1237.

8. McRobbie H, Bullen C, Hartmann-Boyce J, et al. Electronic cigarettes for smoking cessation and reduction. Cochrane Database Syst Rev 2014;(12):CD010216.

9. Kalkhoran S, Glantz SA. E-cigarettes and smoking cessation - Authors' reply. Lancet Respir Med 2016;4:e26-7.

10. Malas M, van der Tempel J, Schwartz R, et al. Electronic Cigarettes for Smoking Cessation: A Systematic Review. Nicotine Tob Res 2016;18:1926-36.

11. Beard E, West R, Michie S, et al. Association between electronic cigarette use and changes in quit attempts, success of quit attempts, use of smoking cessation pharmacotherapy, and use of stop smoking services in 
England: time series analysis of population trends. BMJ 2016;354:i4645.

12. Schraufnagel DE, Blasi F, Drummond MB, et al. Electronic cigarettes. A position statement of the forum of international respiratory societies. Am J Respir Crit Care Med 2014;190:611-8.

13. Reidel B, Radicioni G, Clapp PW, et al. E-Cigarette Use Causes a Unique Innate Immune Response in the Lung, Involving Increased Neutrophilic Activation and Altered Mucin Secretion. Am J Respir Crit Care Med 2018;197:492-501.

14. Tashkin DP, Rennard S, Hays JT, et al. Effects of varenicline on smoking cessation in patients with mild to moderate COPD: a randomized controlled trial. Chest 2011;139:591-9.

15. Tashkin D, Kanner R, Bailey W, et al. Smoking cessation in patients with chronic obstructive pulmonary disease: a double-blind, placebo-controlled, randomised trial. Lancet 2001;357:1571-5.

16. Cahill K, Stevens S, Perera R, et al. Pharmacological interventions for smoking cessation: an overview and network meta-analysis. Cochrane Database Syst Rev 2013;(5):CD009329.

17. Stead LF, Buitrago D, Preciado N, et al. Physician advice for smoking cessation. Cochrane Database Syst Rev 2013;(5):CD000165.

18. Kottke TE, Battista RN, DeFriese GH, et al. Attributes of successful smoking cessation interventions in medical practice. A meta-analysis of 39 controlled trials. JAMA 1988;259:2883-9.

19. Halpern SD, French B, Small DS, et al. Randomized trial of four financial-incentive programs for smoking cessation. N Engl J Med 2015;372:2108-17.

20. Stead LF, Koilpillai P, Fanshawe TR, et al. Combined pharmacotherapy and behavioural interventions for smoking cessation. Cochrane Database Syst Rev 2016;3:CD008286.

21. Poole PJ, Chacko E, Wood-Baker RW, et al. Influenza vaccine for patients with chronic obstructive pulmonary disease. Cochrane Database Syst Rev 2006;(1):CD002733.

22. Wongsurakiat $\mathrm{P}$, Lertakyamanee J, Maranetra KN, et al. Economic evaluation of influenza vaccination in Thai chronic obstructive pulmonary disease patients. J Med Assoc Thai 2003;86:497-508.

23. Wongsurakiat P, Maranetra KN, Wasi C, et al. Acute respiratory illness in patients with COPD and the effectiveness of influenza vaccination: a randomized controlled study. Chest 2004;125:2011-20.
24. Fiore AE, Shay DK, Broder K, et al. Prevention and control of seasonal influenza with vaccines: recommendations of the Advisory Committee on Immunization Practices (ACIP), 2009. MMWR Recomm Rep 2009;58:1-52.

25. Edwards KM, Dupont WD, Westrich MK, et al. A randomized controlled trial of cold-adapted and inactivated vaccines for the prevention of influenza A disease. J Infect Dis 1994;169:68-76.

26. Huang CL, Nguyen PA, Kuo PL, et al. Influenza vaccination and reduction in risk of ischemic heart disease among chronic obstructive pulmonary elderly. Comput Methods Programs Biomed 2013;111:507-11.

27. Tomczyk S, Bennett NM, Stoecker C, et al. Use of 13 -valent pneumococcal conjugate vaccine and 23 -valent pneumococcal polysaccharide vaccine among adults aged $\geq 65$ years: recommendations of the Advisory Committee on Immunization Practices (ACIP). MMWR Morb Mortal Wkly Rep 2014;63:822-5.

28. Walters JA, Smith S, Poole P, et al. Injectable vaccines for preventing pneumococcal infection in patients with chronic obstructive pulmonary disease. Cochrane Database Syst Rev 2010;(11):CD001390.

29. Walters JA, Tang JN, Poole P, et al. Pneumococcal vaccines for preventing pneumonia in chronic obstructive pulmonary disease. Cochrane Database Syst Rev 2017;1:CD001390.

30. Alfageme I, Vazquez R, Reyes N, et al. Clinical efficacy of anti-pneumococcal vaccination in patients with COPD. Thorax 2006;61:189-95.

31. Dransfield MT, Harnden S, Burton RL, et al. Longterm comparative immunogenicity of protein conjugate and free polysaccharide pneumococcal vaccines in chronic obstructive pulmonary disease. Clin Infect Dis 2012;55:e35-44.

32. Bonten MJ, Huijts SM, Bolkenbaas M, et al. Polysaccharide conjugate vaccine against pneumococcal pneumonia in adults. N Engl J Med 2015;372:1114-25.

33. Gross N, Tashkin D, Miller R, et al. Inhalation by nebulization of albuterol-ipratropium combination (Dey combination) is superior to either agent alone in the treatment of chronic obstructive pulmonary disease. Dey Combination Solution Study Group. Respiration 1998;65:354-62.

34. In chronic obstructive pulmonary disease, a combination of ipratropium and albuterol is more effective than either agent alone. An 85-day multicenter trial. COMBIVENT Inhalation Aerosol Study Group. Chest 1994;105:1411-9. 
35. Kew KM, Mavergames C, Walters JA. Long-acting beta2-agonists for chronic obstructive pulmonary disease. Cochrane Database Syst Rev 2013;(10):CD010177.

36. Chong J, Karner C, Poole P. Tiotropium versus longacting beta-agonists for stable chronic obstructive pulmonary disease. Cochrane Database Syst Rev 2012;(9):CD009157.

37. Karner C, Chong J, Poole P. Tiotropium versus placebo for chronic obstructive pulmonary disease. Cochrane Database Syst Rev 2014;(7):CD009285

38. Calzetta L, Rogliani P, Matera MG, et al. A Systematic Review With Meta-Analysis of Dual Bronchodilation With LAMA/LABA for the Treatment of Stable COPD. Chest 2016;149:1181-96.

39. Oba Y, Sarva ST, Dias S. Efficacy and safety of longacting $\beta$-agonist/long-acting muscarinic antagonist combinations in COPD: a network meta-analysis. Thorax 2016;71:15-25.

40. Rodrigo GJ, Price D, Anzueto A, et al. LABA/LAMA combinations versus LAMA monotherapy or LABA/ICS in COPD: a systematic review and meta-analysis. Int J Chron Obstruct Pulmon Dis 2017;12:907-22.

41. Calzetta L, Cazzola M, Matera MG, et al. Adding a LAMA to ICS/LABA Therapy: A Meta-analysis of Triple Combination Therapy in COPD. Chest 2019;155:758-70.

42. Chong J, Leung B, Poole P. Phosphodiesterase 4 inhibitors for chronic obstructive pulmonary disease. Cochrane Database Syst Rev 2017;9:CD002309.

43. Albert RK, Connett J, Bailey WC, et al. Azithromycin for prevention of exacerbations of COPD. N Engl J Med 2011;365:689-98.

44. O'Donnell DE, Flüge T, Gerken F, et al. Effects of tiotropium on lung hyperinflation, dyspnoea and exercise tolerance in COPD. Eur Respir J 2004;23:832-40.

45. Wedzicha JA, Decramer M, Ficker JH, et al. Analysis of chronic obstructive pulmonary disease exacerbations with the dual bronchodilator QVA149 compared with glycopyrronium and tiotropium (SPARK): a randomised, double-blind, parallel-group study. Lancet Respir Med 2013;1:199-209.

46. Yang IA, Clarke MS, Sim EH, et al. Inhaled corticosteroids for stable chronic obstructive pulmonary disease. Cochrane Database Syst Rev 2012;(7):CD002991.

47. Zheng Y, Zhu J, Liu Y, et al. Triple therapy in the management of chronic obstructive pulmonary disease: systematic review and meta-analysis. BMJ 2018;363:k4388.

48. Walters JA, Walters EH, Wood-Baker R. Oral corticosteroids for stable chronic obstructive pulmonary disease. Cochrane Database Syst Rev 2005;(3):CD005374.

49. Wedzicha JA, Calverley PMA, Albert RK, et al. Prevention of COPD exacerbations: a European Respiratory Society/ American Thoracic Society guideline. Eur Respir J 2017. doi: 10.1183/13993003.02265-2016.

50. Walters JA, Tan DJ, White CJ, et al. Different durations of corticosteroid therapy for exacerbations of chronic obstructive pulmonary disease. Cochrane Database Syst Rev 2018;3:CD006897.

51. Wedzicha JA, Calverley PM, Rabe KF. Roflumilast: a review of its use in the treatment of COPD. Int J Chron Obstruct Pulmon Dis 2016;11:81-90.

52. Watz H, Bagul N, Rabe KF, et al. Use of a 4-week uptitration regimen of roflumilast in patients with severe COPD. Int J Chron Obstruct Pulmon Dis 2018;13:813-22.

53. Martinez FJ, Rabe KF, Calverley PMA, et al. Determinants of Response to Roflumilast in Severe Chronic Obstructive Pulmonary Disease. Pooled Analysis of Two Randomized Trials. Am J Respir Crit Care Med 2018;198:1268-78.

54. Ferguson GT, Rabe KF, Martinez FJ, et al. Triple therapy with budesonide/glycopyrrolate/formoterol fumarate with co-suspension delivery technology versus dual therapies in chronic obstructive pulmonary disease (KRONOS): a double-blind, parallel-group, multicentre, phase 3 randomised controlled trial. Lancet Respir Med 2018;6:747-58.

55. Papi A, Vestbo J, Fabbri L, et al. Extrafine inhaled triple therapy versus dual bronchodilator therapy in chronic obstructive pulmonary disease (TRIBUTE): a doubleblind, parallel group, randomised controlled trial. Lancet 2018;391:1076-84.

56. Lipson DA, Barnhart F, Brealey N, et al. Once-Daily Single-Inhaler Triple versus Dual Therapy in Patients with COPD. N Engl J Med 2018;378:1671-80.

57. Sharafkhaneh A, Wolf RA, Goodnight S, et al. Perceptions and attitudes toward the use of nebulized therapy for COPD: patient and caregiver perspectives. COPD 2013;10:482-92.

58. Hanania NA, Mullerova H, Locantore NW, et al. Determinants of depression in the ECLIPSE chronic obstructive pulmonary disease cohort. Am J Respir Crit Care Med 2011;183:604-11.

59. Rochester CL, Vogiatzis I, Holland AE, et al. An Official American Thoracic Society/European Respiratory Society Policy Statement: Enhancing Implementation, Use, and Delivery of Pulmonary Rehabilitation. Am J Respir Crit Care Med 2015;192:1373-86.

60. McCarthy B, Casey D, Devane D, et al. Pulmonary 
rehabilitation for chronic obstructive pulmonary disease. Cochrane Database Syst Rev 2015;(2):CD003793.

61. Ryrso CK, Godtfredsen NS, Kofod LM, et al. Lower mortality after early supervised pulmonary rehabilitation following COPD-exacerbations: a systematic review and meta-analysis. BMC Pulm Med 2018;18:154.

62. Nishi SP, Zhang W, Kuo YF, et al. Pulmonary Rehabilitation Utilization in Older Adults With Chronic Obstructive Pulmonary Disease, 2003 to 2012. J Cardiopulm Rehabil Prev 2016;36:375-82.

Cite this article as: Agrawal R, Moghtader S, Ayyala U, Bandi V, Sharafkhaneh A. Update on management of stable chronic obstructive pulmonary disease. J Thorac Dis 2019;11(Suppl 14):S1800-S1809. doi: 10.21037/jtd.2019.06.12 